\title{
Bio-Optical Response and Coupling with Physical Processes in the Lombok Strait Region
}

\author{
Burton H. Jones \\ Department of Biological Sciences \\ University of Southern California \\ Los Angeles, CA 90089-0371
}

Phone: 213-740-5765

FAX: 213-740-8123

E-mail: bjones@usc.edu

\author{
Emmanuel Boss \\ School of Marine Sciences \\ University of Maine \\ Orono, Maine 04459-5741
}

Phone: $207-581-4378$

FAX: 207-581-4388

E-mail: emmanuel.boss@maine.edu

\begin{abstract}
The optical structure and variability of the Lombok Straits region is poorly understood, but available remotely sensed ocean color indicates that there is a strong optical response and signal associated with the downstream side of the straits. Within the strait, physical processes appear to generate additional optical signals, particularly along the walls of the strait. We believe that these signals provide not only information about the surface layer, but also about the subsurface structure. We propose to use a variety of tools to investigate the bio-optical variability of the region, its response to the physical forcing that drives and modulates the flow through the Strait, and the coupling between in situ structure and remotely sensed ocean color. Optical sensors will be mounted on the UW/APL tow vehicle for 3-dimensional mapping of inherent optical properties providing both spatial and temporal variation for the region. Simultaneously, nearsurface continuous mapping of spectral absorption and attenuation will be obtained with two flow through instruments, one for whole water, and one for filtered water. Nearsurface remote sensing of ocean color will be obtained with a ship mounted HyperSAS remote sensing instrument to measure ocean color with high spectral resolution and without atmospheric interference. Detailed vertical profiles of inherent and apparent optical properties will be obtained to couple the inherent optical properties measured on the tow vehicle with the apparent optical properties and in particular remote sensing reflectance. We expect this project to yield significant insights into the relationship of inherent optical properties with the dominant physical processes in the region, to provide information about the coupling between remotely sensed ocean color and the in situ 3-dimensional processes, and to provide a fundamental understanding of the optical variability of the region which at present is relatively unknown.
\end{abstract}

\section{OBJECTIVES}

The primary goals of this study are to understand:

1. The three-dimensional distribution of inherent optical properties in the region of the Lombok Strait, a relatively remote portion of the world ocean for which relatively little optical data exist.

2. The coupling of bio-optical properties with the physical processes that contribute to and result from the dynamics of a major ocean flow-through strait. 
3. Relationship between the surface expression of three-dimensional ocean processes and the interior processes.

4. The contribution of dissolved and particulate matter to in-water optical properties and their effect on ocean color remote sensing.

\section{RESEARCH QUESTIONS:}

Straits often produce a variety of physical processes that are likely to manifest themselves in optical properties. Physical processes include generation of internal waves and solitons, spawning of eddies, upwelling, as well as strong coastal (sidewall) and near-bottom shear. Each of these processes is expected to influence the local optical properties in potentially distinct ways. Internal waves, fronts, and eddy-like features are readily distinguishable using Ocean Color remote sensing. Specific research questions include:

1. Are there unique bio-optical signatures associated with each of the processes that can serve as effective tracers using remote sensing tools? For example, is bottom resuspension at the strait contributing to ocean color?

2. What are the spatial and temporal scales of variability associated with the bio-optical signatures of these features? For instance, upwelling and an associated eddy may produce a temporal evolution based on an evolving phytoplankton bloom due to injection of macro and micro nutrients that changes signature over time, providing both a spatial scale and perhaps a temporal scaling of the feature. Some upwelling features could have a suspended particle load due to upwelling that transforms to a phytoplankton bloom over time resulting in a shift of the spectral shapes of the optical signatures.

3. If there is a subsurface feature such as an internal wave induced uplifting of a subsurface chlorophyll maximum that was within the first optical depth and therefore detectable by remote sensing, can the depth of the feature be estimated by the spectral characteristics of feature? This should be evaluated using a combination of in situ instruments, ship-based remote sensing, and satellite-based remote sensing.

\section{Proposed Research}

\section{Introduction}

The Lombok Strait in Indonesia a shallow break in the Sunda Island chain and is one of the major passages for the Indonesian flow-through from the Pacific into the Indian Ocean. The mean annual flow is about $1.7-2 \mathrm{~Sv}$ accounting for about $20-25 \%$ of the total southward transport through the Makassar Strait [Murray and Arief, 1988; Arief and Murray, 1996]. Flow through the strait is constrained by the width of $\sim 20 \mathrm{~km}$ between the islands of Lombok and Nusa Penida strait and the sill depth that is on order of 300 meters and a width. Across the strait there is the possibility of a hydraulic jump in the flow as the channel rapidly shallows from about 1400 meters north of the islands in the Java Sea to the sill depth. A number of possible processes will result from the rapid flow through the strait. Significant turbulence results on the down stream side of the sill. Internal waves appear to emanate in both directions (north and south) from the sill (e.g. Figure 1), 


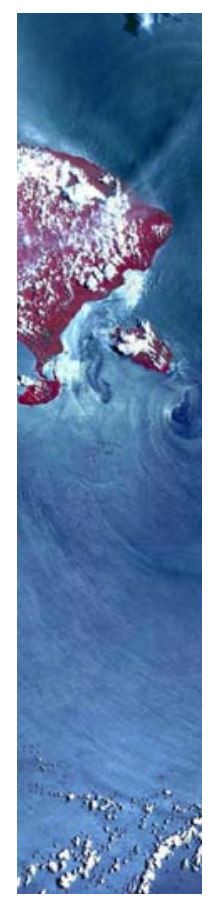

Figure 1. SPOT image showing propagating internal waves from Lombok Strait on October 8, 1998. Source: http://www.ifm.uni-hamburg.de/ers-sar/Sdata/oceanic/intwaves/lombok/

Flow through the strait is modulated by a range of processes including tidal fluctuations, subtropical cyclones, seasonal variations that include the NW and SE Monsoons, sea level oscillations in the Indian Ocean, interannual variations such as El Nino/La Nina events [Murray and Arief, 1988; Arief and Murray, 1996; Hatayama et al., 1996]. The SE Monsoon during MaySeptember (Austral winter) and results in westward flow south of Sunda Islands away from the coast as the south equatorial current (SEC). This flow is typically associated with cyclonic eddies next to coast. These cyclonic eddies elevate nutrients resulting in elevated chlorophyll in the region on the southern side of the islands. The NW monsoon typically occurs during the Austral summer period of November-March and can result in eastward flow (South Java Current) along the southern side of the islands, often damping flow through the straits [Asanuma et al., 2003].

Most of what is known about the optical response to physical forcing in the region of the Lombok Straits comes from remote sensing observations of ocean color. Phytoplankton blooms in the larger region surrounding the Lombok Straits respond to the variations in the physical forcing. Asanuma et al. [2003] have shown that phytoplankton blooms south of Java respond to changes in the winds and that drive the variability in the South Java Current (SJC) during the NW monsoon and the South Equatorial Current (SEC). During the SE monsoon winds from the east or southeast can drive upwelling along the southern coast resulting in an upward flux of nutrients and a subsequent phytoplankton bloom. During periods of non-upwelling the Indian Ocean water south of the Sunda Islands is typically quite low in chlorophyll concentration. However, flow from the Lombok Straits can be characterized by elevated phytoplankton concentrations, and hence a bio-optical signature of the physical dynamics. In the broader region, [Moore et al., 2003] demonstrated that the southeast monsoon drives upwelling in the eastern Banda Sea which is located north of the islands and east of Sulawesi. 
A number of physical processes may result from the large flow through the strait, often reaching velocities in excess of $70 \mathrm{~cm} \cdot \mathrm{s}^{-1}$. The large velocities can generate a variety of smaller scale processes including "lee waves, internal hydraulic jumps, propagating internal solibores, internal tides, separation of flow from lateral boundaries, and headland eddies" [Lee and Martin proposal; Moore and Marra, 2002]. Moore and Marra [2002] concluded that flow through the Ombai Strait between the islands of Alor and Timor results in persistent upwelling and frontal structure that results elevated phytoplankton downstream from the "notch" of the strait. Temperature and salinity maps across Lombok Strait indicate that temperature on the $10 \mathrm{db}$ surface can decrease from more than $29^{\circ} \mathrm{C}$ north of the strait to $<26^{\circ} \mathrm{C}$ south of the strait [Murray et al., 1990]. This has significant implications to the bio-optical signals in the region, since nitrate, and presumably other nutrients, begins to increase with decreasing temperature below $28^{\circ} \mathrm{C}$ [Kinkade et al., 1997]. Availability of nutrients within the euphotic zone will result in increased phytoplankton biomass, and hence a bio-optical signal within a matter of days.

Kinkade et al. [1997] have shown a direct relationship between increased availability of nutrients and increased chlorophyll in the region. Remote sensing of ocean color of the region demonstrates that ocean color can reveal significant information about the flow and processes in the region of the strait (Figure 3; Arnone, personal communication).
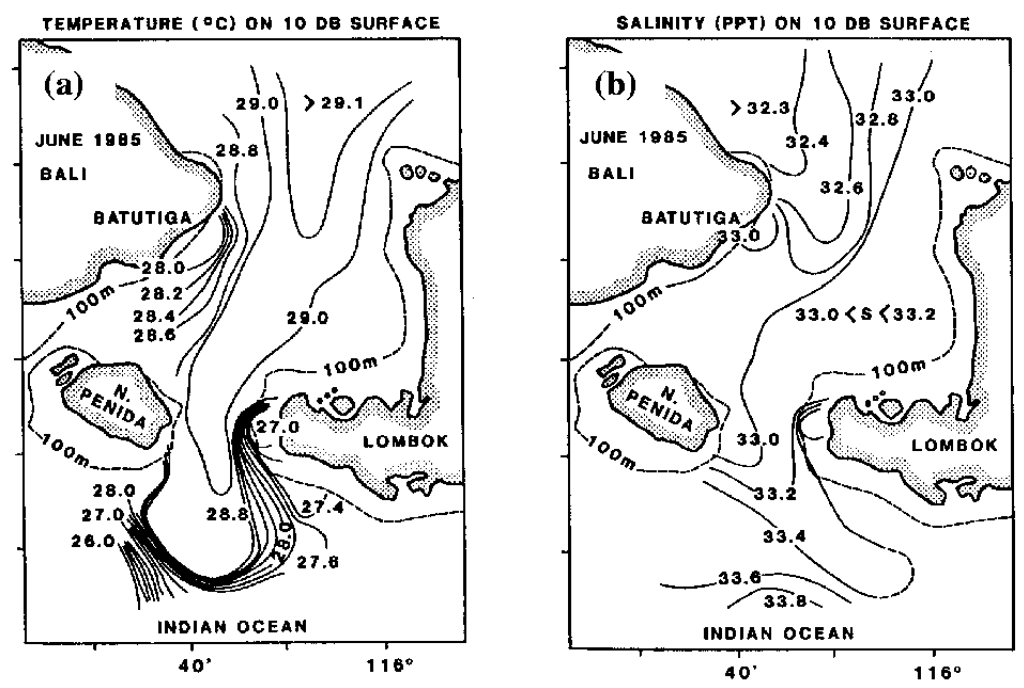

Temperature (a) and salinity (b) on the $10 \mathrm{db}$ surface (from Murray et al., 1990).

Figure 2. Temperature and Salinity sections across the Strait during along the $10 \mathrm{db}$ surface [Murray et al., 1990]. Note the $3^{\circ} \mathrm{C}$ temperature decrease in the front south of the Strait. 


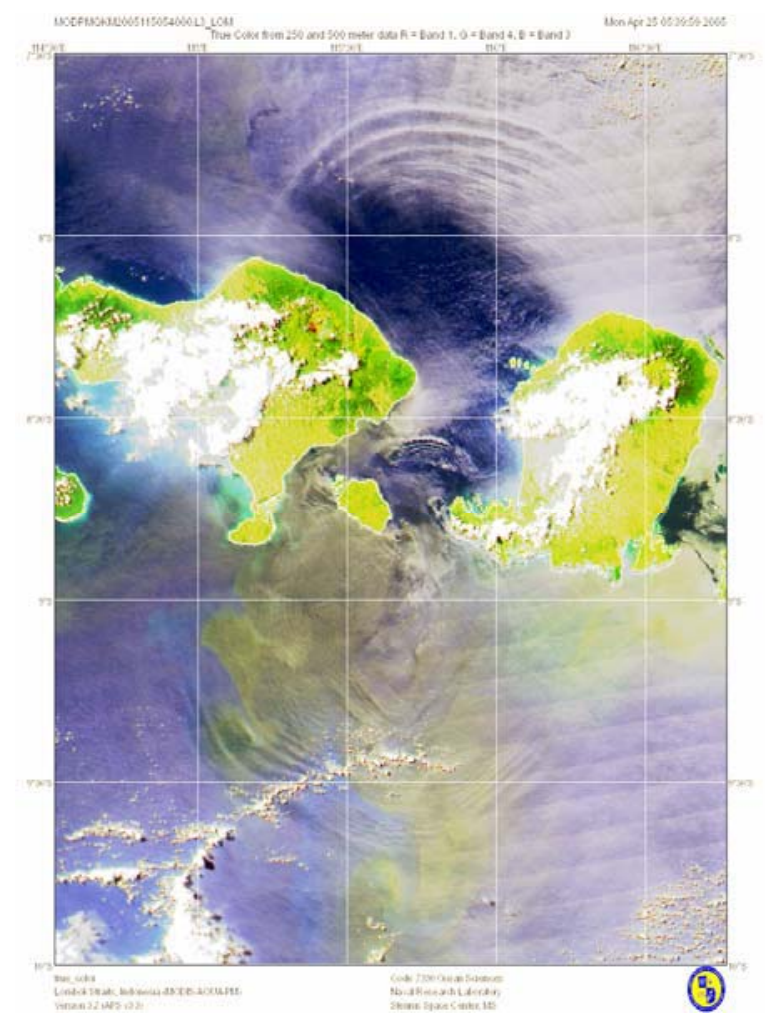

Figure 3. True color image of Lombok Strait and the regions north and south of the strait obtained with the MODIS-Aqua ocean color sensor. Greenish-yellow regions south of the islands and the Strait indicate regions of enhanced chlorophyll on the downstream side of the strait. Brownish areas along both sides of the strait next to the islands that appear brownish may indicate regions of enhanced resuspension due to current shear along the boundaries. Reflection from the internal wave fields is probably due to sun glint from the wave surface, not to the in situ optical properties. Image source: Robert Arnone, Naval Research Laboratory, Stennis, MS.

Apart from what has been shown or described above, little is known about the optical properties and/or distributions in the region. In general, this is a region of very clear water. The large number of coral reefs in the region, remote sensing observations both in this region and to the north [Abu Daya, 2004; Asanuma et al., 2003], indicate that much of the water is quite clear. There are river inputs and phytoplankton blooms in the Makassar strait [Abu Daya, 2004], and significant phytoplankton blooms are modulated by monsoonal variations in regional currents and the eddy field [Asanuma et al., 2003]. There are significant bio-optical signals directly associated with the region south of the Lombok Strait sill (Figure 3). The proximity of these chlorophyll signals immediately adjacent to the sill may indicate a relatively short time scale of response.

Finally, ocean color may reveal processes that are not necessarily clear from remotely sensed sea surface temperature. For example, Pegau et al. [2002] demonstrated that in the Gulf of California during summer ocean color provides a clear indication of the presence of ocean eddies, but due to intense solar heating, temperature does not clearly delineate the eddies. Solar heating can cause nearsurface heating of the ocean skin. The ocean skin temperature, and hence remotely sensed SST, may then mask the underlying physical structure and processes. Ocean color, however, because it integrates the upwelling light field from the first optical depth 
provides information about the structure beneath the skin. Ocean color may therefore provide a truer picture of the ongoing physical processes than remotely sensed SST.

\section{Observational Program and Analysis}

Two research cruises are planned for this project: one during the SE Monsoon in July/August 2007 (Austral winter) and one during the NW Monsoon in February/March 2008 (Austral summer). The physical oceanography component of these cruises will be led by Craig Lee (UWAPL). We will collaborate with Lee to add optical sensors to the towed undulating vehicle for mapping 3-dimensional distributions of physical and bio-optical properties. Other complementary observations potentially include ocean color remote sensing (Arnone, NRLStennis), and in situ primary productivity measurements using a fast repetition rate fluorometer (Marra, LDEO).

We expect to use four types of observations that will complement both the physical and remote sensing efforts. The proposed observations are intended to evaluate the utility of optical signatures as tracers for the physical processes associated with the strait dynamics.

1. Optical sensors will be mounted on the UW-APL towed undulating vehicle for mapping 3-dimensional distributions of inherent and apparent optical properties that should respond to the physical processes of the straits. We expect to deploy a Wetlabs ACS hyperspectral absorption/attenuation meter, a Wetlabs BB9 9-wavelength backscatter sensor, CDOM and chlorophyll fluorometers, and, if possible, Satlantic radiometers for measurements of downwelling irradiance and upwelling radiance (e.g., Figure 4).

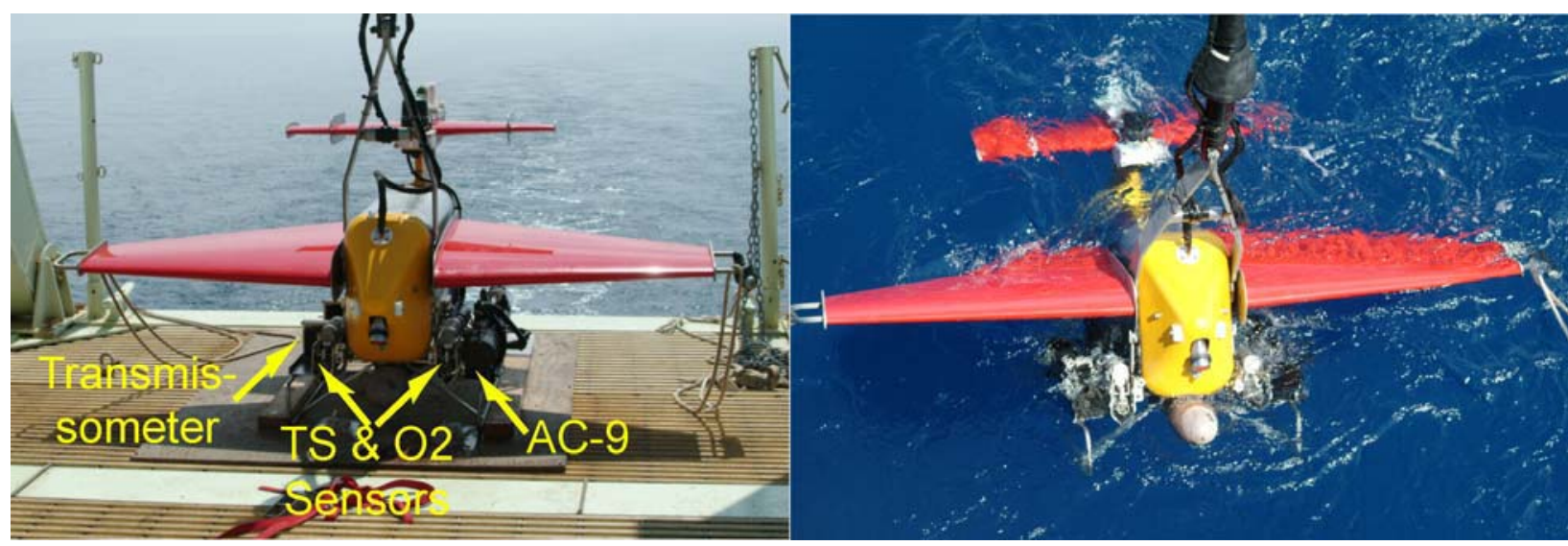

Figure 4. These pictures show the University of Washington Trisoarus tow vehicle equipped with the USC AC-9 absorption attenuation meter, beam transmissometer, chlorophyll and CDOM fluorometers, O2 sensor, and physical sensors for T, C, and ADCP current profiling. This configuration was used in the Adriatic Sea for the Dolce Vita project.

The optical sensors mounted on the tow vehicle enable the simultaneous 3-dimensional mapping of physical and bio-optical variables. The bio-optical variables often provide an invaluable tracer and index of the physical dynamics occurring in the water column. In the Japan/East Sea (the ONR Japan/East Seas [JES] project) the subpolar front was mapped repeatedly using a Seasoar equipped with both the absorption/attenuation meter and a multiwavelength optical backscatter sensor. During the late spring/early summer period, optical backscatter provided insight into the front, the associated subduction, and transport of particles along the subduction feature (Figure 5). 


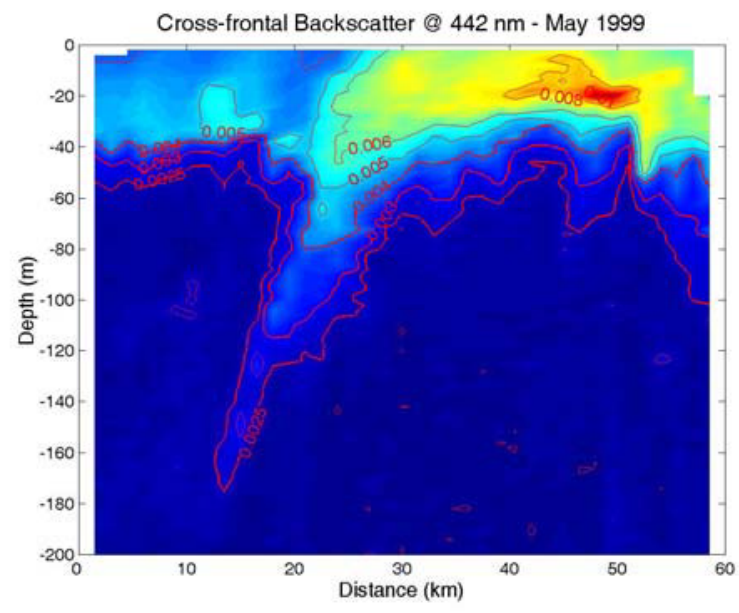

Figure 5. Frontal cross-section of the subpolar front obtained with a Hydroscat 6 wavelength backscatter sensor mounted on the WHOI Seasoar. The image shows the accumulation of particles, indicated by high backscatter, on the northern (right) side of the front. Subduction at the front transports particles from this surface accumulation downward to a depth of at least 180 meters. Additional sections along the front demonstrate that subduction was continuous along the front.

Deployment of the Wetlabs AC-9 (absorption/attenuation meter) on the Trisoarus tow vehicle in the Adriatic Sea in 2003 provided an opportunity to examine the response of the bio-optical fields to strong physical forcing during winter Bora wind events, and to the river inflow from the Po River in the northwest Adriatic. Figure 6 (upper panel) demonstrates the correspondence between features in the bio-optical structure with temperature and salinity structure during a winter Bora wind event. Higher suspended particle load and dissolved organic matter absorption are correlated with lower salinity water on the north side of the front. The lower panel shows the temporal evolution of the front for both temperature and attenuation at $650 \mathrm{~nm}\left(\mathrm{c}_{650}\right)$ along the second line from the right (in the upper panels) over a period of about 3 days. $\mathrm{c}_{650}$ shows clearly the evolution of the front as well as the location of the lower salinity water north of the front. Because this feature extends to the surface, remote sensing reflectance from this would provide an indication of salinity variations as well as the suspended particle load. 

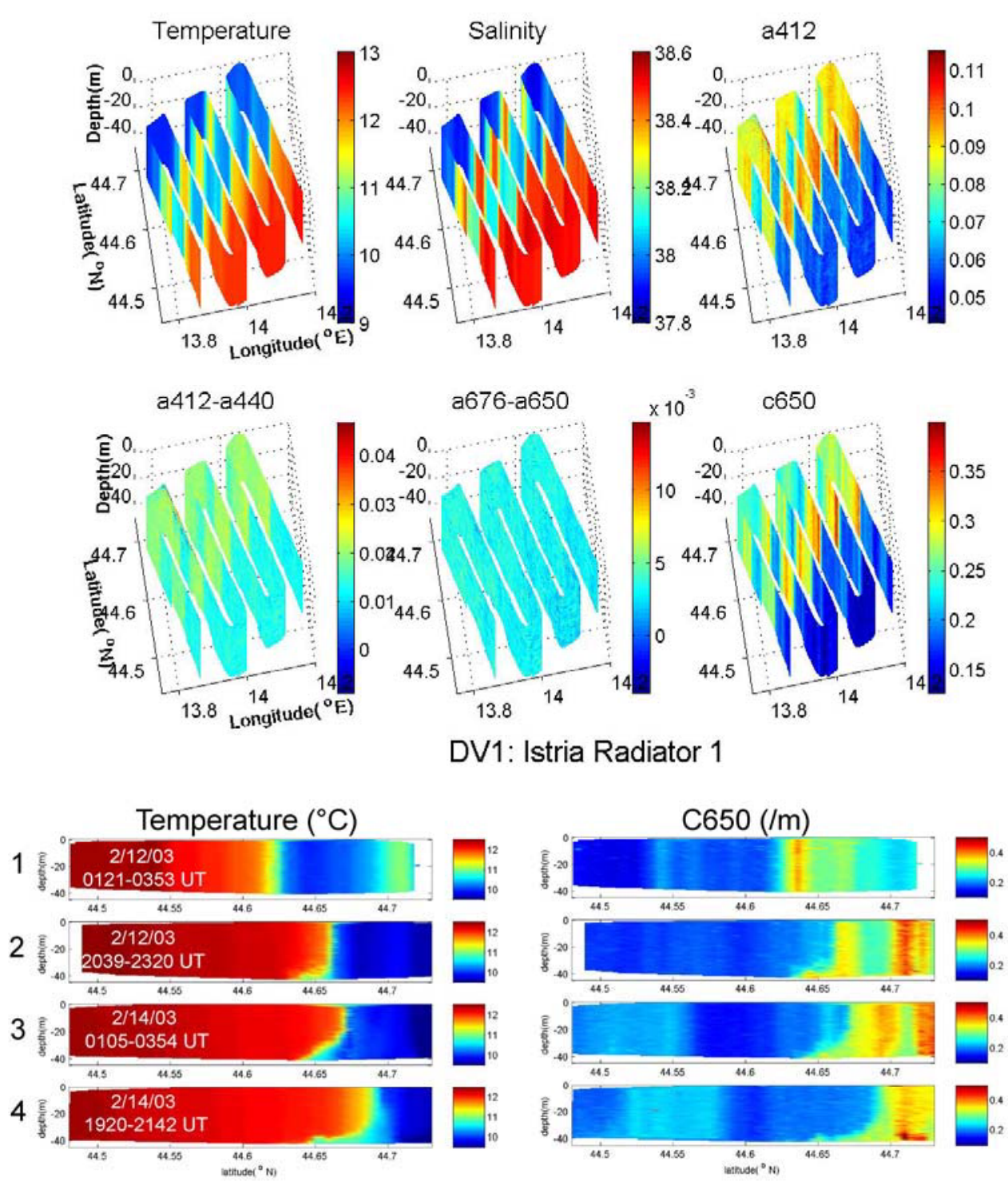

Figure 6. Trisoarus radiator map of a frontal region south of Istria (Croatia) during a strong winter Bora event. In the top group, four of the images are of optical variables from the AC9: a412 and 'a412-a440' are indicative of absorption due to dissolved organic matter, 'a676-a650' indicates the absorption due to phytoplankton chlorophyll, and $\mathbf{c 6 5 0}$ is the attenuation at $650 \mathrm{~nm}$ that results from the suspended particles.

2. Continuous nearsurface underway measurements of inherent optical properties will be obtained from the ships underway seawater flow system. These measurements will include unfiltered and filtered absorption/attenuation measurements using either Wetlabs AC9 or ACS instruments, spectral backscatter, and particle size spectra with the LISST100. Both this set of measurements and the following item are important for interpreting remotely sensed ocean color observations.

These measurements are especially important for the nearsurface variability in the inherent optical properties that would be most directly observable from satellite. These measurements enable us to distinguish between the signals that result from phytoplankton, abiotic suspended particulate material, and dissolved organic matter that can have either a marine or terrestrial 
origin. By combining optical properties we are able to differentiate between organic and inorganic particles (e.g. Fig 7).
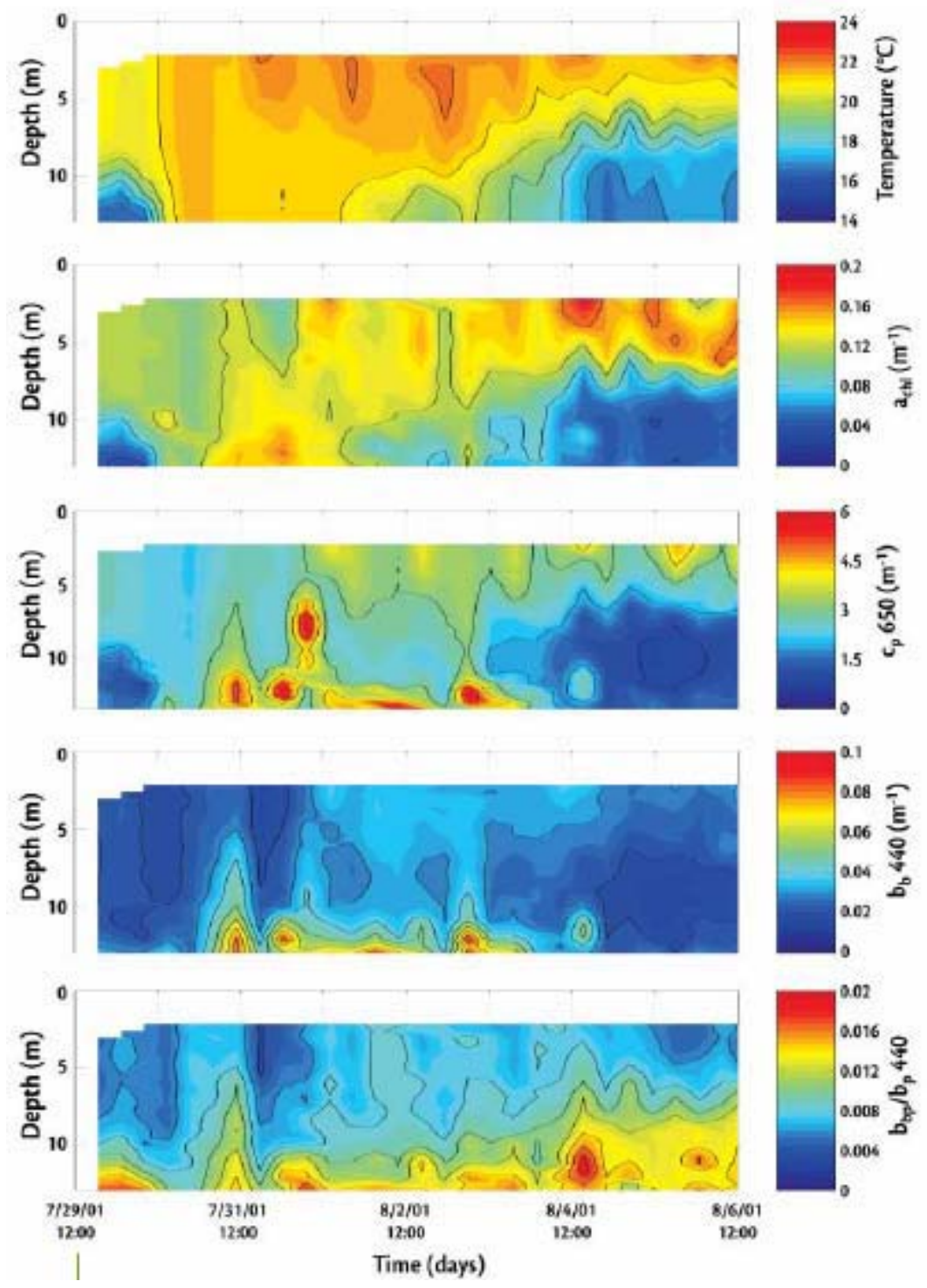

Figure 7. Eight-day time series of water temperature, chlorophyll absorption (based on the $676 \mathrm{~nm}$ absorption line height), beam attenuation coefficient at $650 \mathrm{~nm}\left(c_{\mathrm{p}} 650\right)$, particulate backscattering coeffi cient at $440 \mathrm{~nm}\left(b_{b p} 440\right)$, and the particulate backscattering ratio (bbp/bp 440; the ratio of particulate backscattering to particulate scattering) at $440 \mathrm{~nm}$. All of these data were collected by the LEO-15 profiling mooring. Periods of a highly stratified water column (7/29 and 8/4-5/2001) are characterized by relatively low backscattering while a less-stratified period (7/30-8/3/2001) exhibit higher backscattering, in particular near the bottom due to sediment resuspension. The backscattering ratio is high near the bottom and low near the surface throughout the time series suggesting that high index of refraction sediments dominate near the bottom while low index of refraction phytoplankton dominate near the surface (From Boss et al., 2004).

3. Continuous ship-based measurements of "on the water" hyperspectral remote sensing reflectance will be obtained with a Satlantic HyperSAS system. The HyperSAS provides high spatial and spectral resolution of remotely sensed remote sensing reflectance without 
atmospheric interference, which is key to linking in water optical properties distributions with remotely sensed optical signals.

A picture and example data set from the Satlantic MicroSAS (predecessor of the HyperSAS) is shown in Figure 8. This data set will be invaluable for making the link between the threedimensional distributions of in situ inherent optical properties with remotely sensed ocean color (without having to compensate for the atmosphere in between the ocean surface and the remote sensing detector). Comparison with satellite ocean color (in collaboration with Arnone's group at NRL) will provide the necessary data to choose the most appropriate atmospheric correction model for this region and time of year.
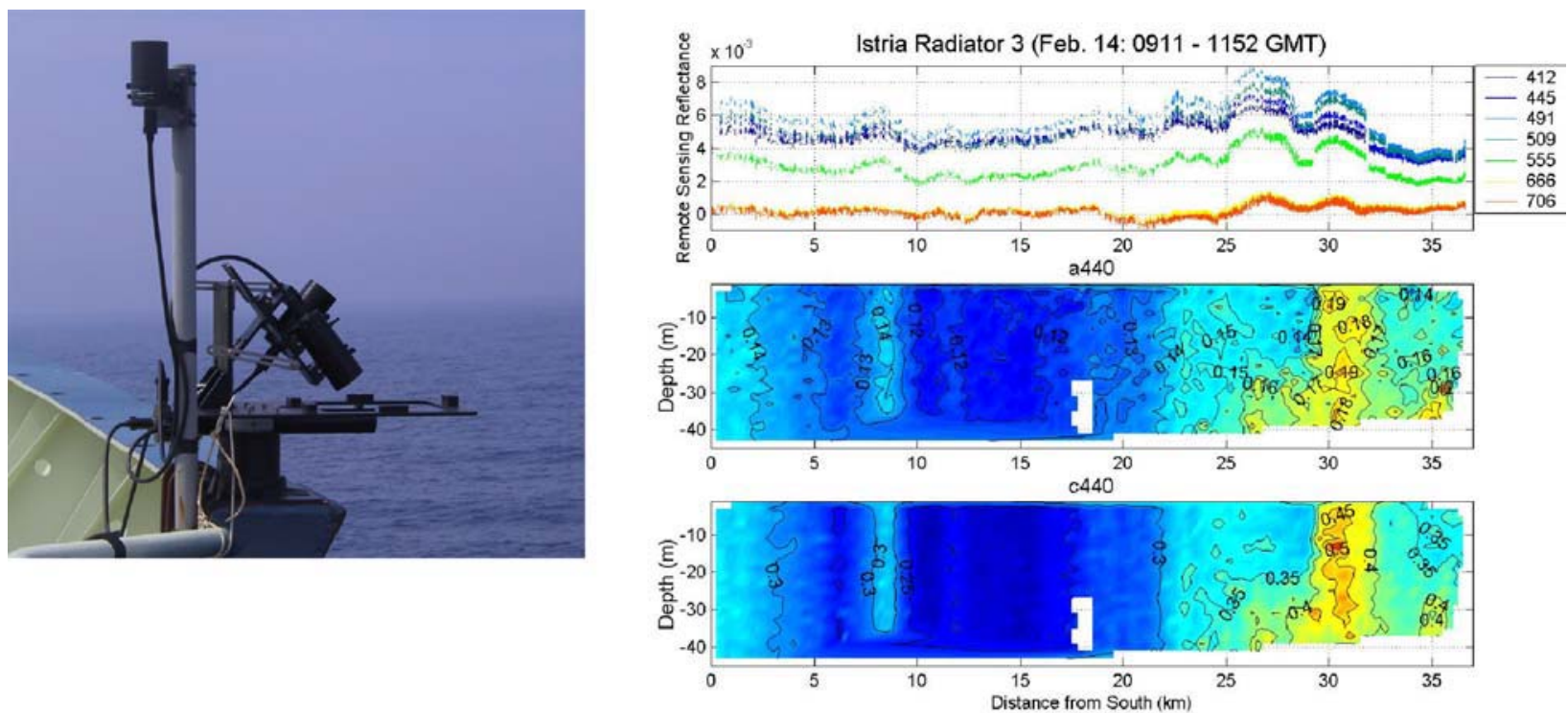

Figure 8. Picture of the Satlantic MicroSAS deployed on the R/V Knorr in the northern Adriatic Sea on the leftt, and on the right a section across a frontal zone from the Istrian front during the winter Bora event (same feature as shown in Figure 6). The top panel shows the remote sensing reflectance by wavelength across the front, and the lower two panels show both the absorption (a440) and attenuation (c440) measured with the AC9 on the Trisoarus tow vehicle.

4. Station based high resolution vertical profiles of physical, inherent optical, and apparent optical properties will be obtained with a bio-optical profiler. These measurements will likely be made in conjunction with CTD-rosette casts to provide verification and interpretation of the in situ towed observations and the remotely sensed apparent optical properties.

Station based profiling is used as verification or ground truthing for the observations obtained with the towed vehicle, HyperSAS, and continuous nearsurface measurements of inherent optical properties. It provides for sampling of vertical detail as well as allowing for the deployment of complementary radiometric sensors that are, in some cases, not deployable on the tow vehicle. For instance, if the Trisoarus tow vehicle is used for the 3-dimensional mapping, it is not suitable for deployment of in situ radiometers. The vehicle attitude (yaw, pitch and roll) prevents it from obtaining good quality radiometric measurements. The coupling between the radiometric processes (apparent optical properties including remote sensing reflectance), inherent optical properties (absorption, scattering, attenuation), and 
property relationships (ie. Chlorophyll concentration, total suspended material, particulate organic carbon) can be established from the station based sampling. Sampling for these observations is performed with a bio-optical profiling package (Figure 9) and a standard CTDRosette profiling system. The Bio-Optical Profiling Package is equipped with a SeaBird 9/11+ CTD, Wetlabs ACS absorption attenuation meter for whole water absorption and attenuation, Wetlabs AC9 equipped with a 0.2 micron filter for measurements of the dissolved organic absorption spectra., a Hydroscat-6 6-wavelength backscatter sensor, Satlantic radiometers for measurement of downwelling irradiance and upwelling radiance which is relevant to remote sensing reflectance, a transmissometer, and fluorometers for chlorophyll fluorescence and colored dissolved organic matter (CDOM) fluorescence.

We expect to modify this system to a SLOWDROP system by equipping it with flotation to slow the profile rate to about $20 \mathrm{~cm} \cdot \mathrm{s}^{-1}$. The SLOWDROP system allows the package to profile away from the ship where it is not subject to ship shadow, to drop independent of a direct support cable to the ship, thus removing the influence of ship motion on the profile.

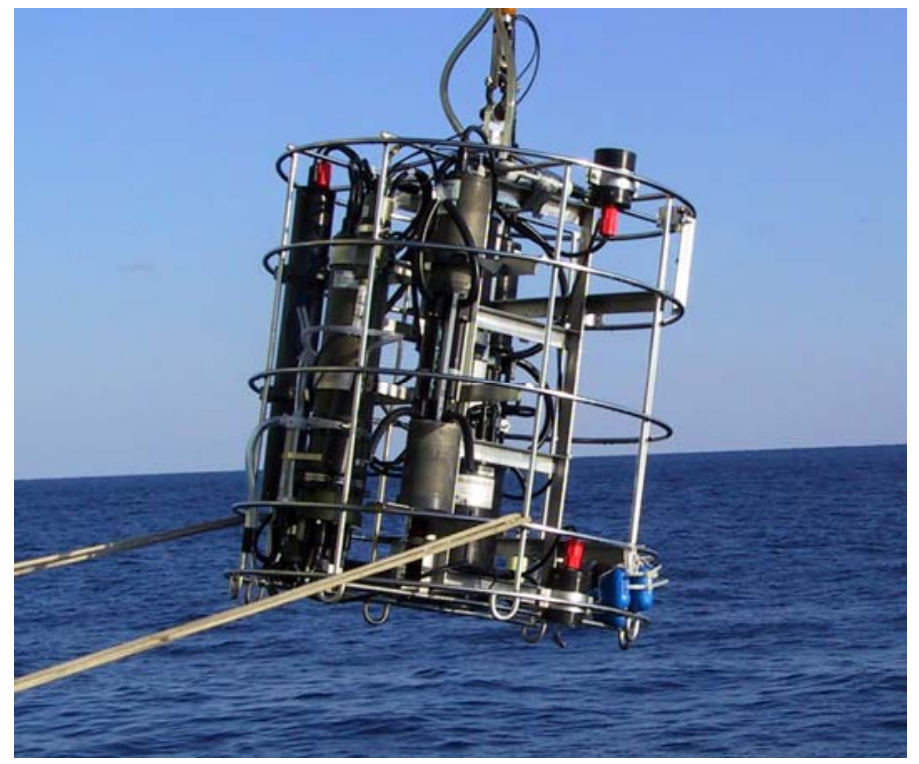

Figure 9. Bio-Optical Profiler being deployed in the Adriatic during the Dolce Vita project. The profiler carries a CTD, 2 absorption/attenuation meters (one filtered, one unfiltered), multi-wavelength backscatter sensor, downwelling irradiance and upwelling radiance radiometers, chlorophyll and CDOM fluorometers, and a transmissometer. This package will be modified for SLOWDROP operations for the proposed effort. This will remove problems due to ship's shadow and ship's motion. Estimated profile speed will be about 20 $\mathrm{cm} \cdot \mathrm{s}^{-1}$.

5. Water samples for ground truthing the link between optical signature and in-water biogeochemistry; HPLC pigments, POC, Nutrient, and TSM.

These water samples will be drawn from the CTD rosette system at depths that are relevant to the bio-optical features and will be frozen and shipped back to our laboratories in the United States for laboratory analysis. These are to provide ground truth numbers for correlating the optical measurements to the corresponding physical units of concentration of the appropriate components that contribute the bio-optical signals. We expect a limited number of samples that will be obtained from various locations 


\section{Schedule}

2006 - Equipment preparation, cruise planning, and project coordination

2007 - July/August, 2007 - SE Monsoon Cruise - 21 days

2008 - February 2008 - NW Monsoon Cruise - 21 days

\section{Deliverables:}

1. Inherent optical properties and their spatial distributions will be provided for a remote region of the ocean for which very little in situ optical data currently exist.

2. The relationship of the distributions of the inherent optical properties to the physical structure and processes of the region will be evaluated.

3. An investigation of the possibility of using remotely sensed optical properties to estimate the depth of in situ distributions.

\section{Interactions with Other Programs}

1. Lee et al. (UW) Trisoarus/Triaxus operations. Craig Lee and his group are responsible for the towed vehicle surveys that will be carried out as part of this program. We will coordinate our efforts directly with his group's effort. Our optical sensors will be deployed on the UW/APL tow vehicle. We have worked closely together on several cruises, are familiar with each others operations, and collaborate closely both on planning the field efforts and analysis of the data sets.

2. Arnone (NRL) Remote Sensing - Robert Arnone is proposing to obtain and analyze remote sensing data (both AVHRR and ocean color data) for the cruise. We have worked closely with Arnone in the same efforts that we have collaborated with Craig Lee. We will work closely with Arnone and interpreting and correlating the satellite imagery with in situ observations physical and bio-optical observations.

3. Marra (LDEO/Columbia) Primary productivity. John Marra has proposed to integrate a Satlantic Fast Repetition Rate Fluorometer with the UW/APL tow vehicle. His observations coupled with our bio-optical measurements would provide a direct coupling of the physical processes, and the biological rate processes that are responsible for phytoplankton growth and production, and hence one of the key factors of the bio-optical signals in an ocean system. Our observations will benefit his effort by providing detailed 3-dimensional distributions of phytoplankton biomass and the light field that provides the energy for photosynthesis.

4. Ffield and Gordon (LDEO/Columbia) modeling - We expect that our observations, coupled with the physical observations of Craig Lee will provide input and/or verification for the numerical modeling efforts of Ffield and Gordon.

5. Flament (UH) and Poulain (OGS) - The proposed HF radar effort of Flament and Poulain will be valuable for guiding and tuning the sampling plan for the towed vehicle mapping. In addition, this data set will provide valuable information for evaluating transport, identifying key features in the nearsurface circulation, and overall analysis of the data sets. 


\section{Capacity Building / Students}

An ONR sponsored training program Ocean Optics and Remote Sensing will be offered in summer 2007 (pending approval of funding). This provides an excellent opportunity to send Indonesian students to the program for training in key areas of our research effort.

The original proposal included a graduate student for Emmanuel Boss, University of Maine to assist with analysis of the data set. The student has been removed from the revised budget. Our discussions indicate that provision for the student will be provided during the project. 


\section{REFERENCES}

Abu Daya, M.I., Coastal Water Quality Monitoring with Remote Sensing in (East Kalimantan) Makassar Strait, Indonesia, M.S. thesis, International Institute for Geo-information Science and Earth Observation, Enschede, Netherlands, 2004.

Arief, D., and S.P. Murray, Low-frequency fluctuations in the Indonesian throughflow through Lombok Strait, Journal of Geophysical Research-Oceans, 101 (C5), 12455-12464, 1996.

Asanuma, I., K. Matsumoto, H. Okano, T. Kawano, N. Hendiarti, and S.I. Sachoemar, Spatial distribution of phytoplankton along the Sunda Islands: The monsoon anomaly in 1998, Journal of Geophysical Research-Oceans, 108 (C6), -, 2003.

Boss, E., W.S. Pegau, M. Lee, M. Twardowski, E. Shybanov, G. Korotaev, and F. Baratange, Particulate backscattering ratio at LEO 15 and its use to study particle composition and distribution, Journal of Geophysical Research-Oceans, 109 (C1), -, 2004.

Hatayama, T., T. Awaji, and K. Akitomo, Tidal currents in the Indonesian Seas and their effect on transport and mixing, Journal of Geophysical Research-Oceans, 101 (C5), 1235312373, 1996.

Kinkade, C., J. Marra, C. Langdon, C. Knudson, and A.G. Ilahude, Monsoonal differences in phytoplankton biomass and production in the Indonesian Seas: Tracing vertical mixing using temperature, Deep-Sea Research Part I-Oceanographic Research Papers, 44 (4), 581-592, 1997.

Moore, T.S., and J. Marra, Satellite observations of bloom events in the Strait of Ombai: Relationships to monsoons and ENSO, Geochemistry Geophysics Geosystems, 3, -, 2002.

Moore, T.S., J. Marra, and A. Alkatiri, Response of the Banda Sea to the southeast monsoon, Marine Ecology-Progress Series, 261, 41-49, 2003.

Murray, S.P., D. Arief, J.C. Kindle, and H.E. Hurlburt, Characteristics of circulation in a Indonesian Archipelago Strait from hydrography, current measurements and modeling results, in The Physical Oceanography of Sea Straits, edited by L. Pratt, pp. 3-23, Kluwer Academic Publishers, Norwell, MA, 1990.

Pegau, W.S., E. Boss, and A. Martinez, Ocean color observations of eddies during the summer in the Gulf of California, Geophysical Research Letters, 29 (9), -, 2002. 


\title{
BIOGRAPHICAL SKETCH:
}

\author{
Emmanuel Boss \\ School of Marine Sciences \\ University of Maine, 5741 Libby Hall \\ Orono, ME 04469 \\ Tel.: (207) 581-4378 \\ Fax: (207) 581-4388 \\ Email: emmanuel.boss@maine.edu
}

a. Professional Preparation.

1990 B. S. Hebrew Univ., Math, Physics, Honors

1991 M. S. Hebrew Univ., Oceanography, Highest honors, (advisor Nathan Paldor)

1996 Ph. D. Univ. of Washington, Oceanography (advisor Luanne Thompson)

1997 Postdoc, Univ. of Washington., Oceanography (advisor MJ Perry)

1998 Postdoc, Oregon State Univ., Oceanography (advisor JRV Zaneveld)

b. Appointments.

1999-2002 Assistant Professor (Sr Res), Oregon State Univ., Oceanography

2002-2005 Assistant Professor, School of Marine Sciences, Univ. of Maine

2005-present Associate Professor, School of Marine Sciences, Univ. of Maine

B. 5 Pertinent publications.

Peng, W., E. Boss, and C. Roelser, 2005. Uncertainties of inherent optical properties obtained from semi-analytical inversions of ocean color. Applied Optics, 44, 4074-4085.

Boss E., W. S. Pegau, M. Lee, M. S. Twardowski, E. Shybanov, G. Korotaev, and F. Baratange. 2004. The particulate backscattering ratio at LEO 15 and its use to study particles composition and distribution. J. Geophys. Res., 109, C0101410.1029/2002JC001514.

Chang G. C., T. D. Dickey, O. M. Schofield, A. D. Weidemann, E. Boss, W. S. Pegau, M. A. Moline, and S. M. Glenn, 2002. Near shore physical forcing of bio-optical properties in the New York Bight. Journal of Geophysical Research, 107, 3133, 10.1029/2001JC001018.

Pegau W. S., E. Boss and A. Martinez, 2002. Ocean color observations of eddies in the Gulf of California during the summer. Geophysics review letters, 29(9), 10.1029/2001GL014076

Boss, E., W. S. Pegau,W. D. Gardner, J. R. V. Zaneveld, A. H. Barnard., M. S. Twardowski, G.

C. Chang and T. D. Dickey, 2001. The spectral particulate attenuation and particle size distribution in the bottom boundary layer of a continental shelf Journal of Geophysical Research, 106, 9509-9516. 


\section{Five other significant publications:}

Behrenfeld, M. J., E. Boss, D. A. Siegel, and D. M. Shea, 2005. Carbon-based ocean productivity and phytoplankton physiology from space. Global Biogeochemical Cycles, 19(1), GB100610.1029/2004GB002299.

Boss E., and J. R. V. Zaneveld, 2003. The effect of bottom substrate on inherent optical properties; evidence of biogeochemical processes. Limnology and Oceanography, 48, 346-354.

Twardowski M., E. Boss, J. B. Macdonald, W. S. Pegau, A. H. Barnard, and J. R. V. Zaneveld, 2001. A model for estimating bulk refractive index from the optical backscattering ratio and the implications for understanding particle composition in case I and case II waters. Journal of Geophysical Research, 106, 14,129-14,142.

Boss E. and W. Scott Pegau, 2001. The relationship of light scattering at an angle in the backward direction to the backscattering coefficient. Applied Optics, 40, 5503-5507.

Karp-Boss, L., Boss, E. and P. Jumars. 1996. Nutrient fluxes to planktonic osmotrophs in the presence of fluid motion. Oceanography and Marine Biology, An Annual Review., 34, 71-107.

\section{Collaborators}

M. Behrenfeld (NASA Goddard), B. Bergamaschi (USGS, Sacramento), G. Chang (UC, Santa Barbara), T. Clayton (USGS. St Pete), K. Fennel (Rutgers), P. Hill (Dalhousie), P. Jumars (U

Maine), S. Pegau (OSU), M. J. Perry (U. Maine), S. Riser (U. Washington), C. Roesler

(Bigelow), M. S. Twardowski (WetLabs), R. J. V. Zaneveld (OSU, WetLabs).

\section{Advisors and advisees}

S. Hearing, P. Wang, W. Salde, M. Estapa, C. Russo, T. Bergman.

N. Paldor, L. Thompson, M. J. Perry and R. J. V. Zaneveld 


\section{FACILITIES:}

\section{E. Boss, University of Maine}

Dr Boss has a fully functioning laboratory equipped with the latest ocean going optical sensors (LISST-100, LISST-FLOC, bb-9, ac-9, ac-s, beam transmissometers

(2), LSS, chlorophyll and CDOM fluorometers) many of which will be used as part of this project. He has access to additional equipment in Dr. MJ Perry lab (including a spectrophotometer and a coulter counter) and at the environmental optics laboratory at Oregon State University (through an agreement with Drs R. Zaneveld and S. Pegau). Dr Boss is routinely performing calibrations of optical equipment in his lab using ultra pure water produced in Dr. M. Wells lab and standard calibration beads. Computer resources available to the PI at U of Maine include 4 PCs linked to the internet with a 10 base $\mathrm{T}$ connection. Data storage capabilities and ability to disseminate data on the WWW are also available. Dr Boss has access to ocean color data from SeaWIFS and MODIS. U. of Maine has a local receiving station directed by Dr. A. Thomas. 